\title{
Significance of Power Quality in Power Systems
}

\author{
Muhammad Aamir \\ Department of Electrical Engineering \\ University of Engineering and Technology Peshawar \\ amirktk5593@gmail.com \\ Received: 19 January, Revised: 24 February, Accepted: 06 March
}

\begin{abstract}
In this paper a review on power quality is discussed. Power quality is becoming a significant issue because of many reasons; few of these reasons are many instruments that are gaining familiarity in use to enhance the performance of energy system like advance power electronics and drivers of adjustable-speed motor. But the problem of using these instruments is that they enhance the level of harmonic components in distribution network.The control dependent devices and loads that relay on the microprocessor and microcontroller are most prone to problem of quality issue. Due to distortion in the system of energy there is severe effect on the interconnected networks that are common today. The reason behind it is the failure of an entire component. There is increasing growth of problems of voltages as voltage harmonics, over voltage, under voltage, etc. are causing awareness of issues in the power quality. So, the need of both better and high quality of power is increasing extremely among end users. Considering different cases any suitable option can be selected for power quality improvement.
\end{abstract}

Keywords - Power Quality, Power Sytem

\section{INTRODUCTION}

The quality of power defined by international electrical and electronic engineering as sensitive load should be attached to a powering system such that the system is grounded and the supply power to the load is suitable for operation. Quality of power and reliability of power source are two aspects of any power system [1]. Earlier power quality was not considered is the main motto of the power system, continuity of electric supply was considered is the main concern. But nowadays the power system has changed to very complex networks. Nowadays the need of the time is it requires both the permanency of power supply and the power source quality.

\section{POWER QUALITY}

An ideal voltage or current signal is a signal with constant varying amplitude and constant frequency so that its shape is purely like sinusoidal signal. Current and voltage quality is defined as the load voltage or current must have the same waveform as the source. Any distortion in load voltage or current will be considered is the deviation from the source voltage or current is low power quality signal. Because of this deviation a device connected may produce less fruitful results than expected. The different meaning and importance of power quality is that the design of a device should be noise free in the grounding system and no voltage alteration should occur. However, the possibility of using the available power for processing of different types of loads is considered by the end users dependent on power quality. The issue of power quality can severely affect the distribution network system. Thus, the motive of our work is to enhance the power quality. Quality of Power plays in important role in power system. Low power quality effect consumer in many ways [2], it causes distortion, electrical interruption in power appliances, decaying life of industrial equipment's, and more seriously it can be detrimental to life of human being. So power quality should be maintained in a best available limit to minimize loss and to keep electrical devices safe from contingencies and proper operation of electrical load.

Power quality issues have to be minimized using advance electronic based custom power devices [3]. There are many custom power devices which plays an important starring role for solving any desired solution for different problem in power quality. Dynamic voltage restorer (DVR) is a compensation device among different compensating devices, which can be used for unbalance load voltages, and voltage sage and swell problems [4]. DVR is only limited to voltage related problems. Power system is a complex network and any contingency in such a complex system is also complex so we need a custom device that can deal with different issues. One of these custom devices is Unified power quality conditioner (UPQC) [5]. Hirofumi Akagi designed this custom power device in 1995. This custom device can help us solve problems related to voltage sag, swell, current imbalance, reactive power, total harmonic distortion and flickering. UPQC is still in research and is very promising in solution to our problems.

Power quality as it is deal in most important aspect today was not given that much importance in past [1]. But it was not left as it has no importance. Solutions were designed accordingly to the problems that were persistent at that time. Passive elements were used by designer as solution which sometime work, if not then they had to be physically re- 
operated manually. After the invention of semiconductor devices in 1932 the control of electrical power system became easy [6]. Large control systems were converted into portable control systems. For high electrical equipment's control system using semiconductor were designed, which were processing more fast, accurately and were more economical than previous system. So adaptation of these semiconductor devises introduces new problems and again using these semiconductor new solutions were presented.

Nowadays electrical devices made of semiconductor devices are very sensitive to many contingencies. Power electronic converters are non-linear devices, which enhances the reactive power capability of transmission network by introducing load current and voltage [2]. This load current and voltage introduces harmonic to the system, causing loss of power, abnormality in current and voltage waveform from ideal sine wave to distorted sine wave, and flickering. Overall power quality is reduced by these power electronic converters. Therefore compensation is required to avoid these contingencies and to recover the quality of power according to the standard set by IEEE.

\section{NEED OF BETTER POWER QUALITY}

For every problem there is a solution. Power quality is becoming a significant issue because of many reasons; few of these reasons are discussed as follows

- There are many instruments that are gaining familiarity in use to enhance the performance of energy system like shunt capacitors and drivers of adjustable-speed motor. But the problem of using these instruments is that they enhance the level of harmonic components in distribution network.

- The control dependent devices and loads that relay on the microprocessor and microcontroller are most prone to problem of quality issue.

- Due to distortion in the system of energy there is severe effect on the interconnected networks that are common today. The reason behind it is the failure of an entire component.

- There is increasing growth of problems of voltages as over voltage, under voltage, voltage drop etc. is causing awareness of issues in the power quality. So, the need of both better and high quality of power is increasing extremely among end users.

\section{Motivation}

For mitigating the issues regarding currents and voltages harmonics different custom devices has been introduced. Among these devices UPQC is preferred because of its hybrid APF. The series APF is used to compensate for the load voltages; it induces compensated voltage at the PCC. Where is shunt active power filtering induces current at PCC, eliminate distortion in current waveform, compensation of the load reactive power and the maintaining constant voltage of DC link capacitor. This gives me the motivation to investigate the total harmonic distortion in distributed power supply and improve it by using UPQC.

\section{IMPACT OF POWER QUALITY ON LOAD}

Power electronic based devices have an advantage of cost reduction and disadvantage of sensitivity to reduction in power quality. Its impact is on both, the high power industrial load and on low power domestic load. Most of the loads are quite sensitive to the deviation in voltage or current waveform. Most common problems in power quality for both industrial and domestic load are low power factor, distortion and unbalance in supply voltage, DC components in load voltages and current (DC OFFSET) [1-3].

Power factor is because of increase in current in power appliances resulting in drawing more current from the source causing power loss and drop in line voltages [7]. Harmonics in current and voltage causes distortion in waveform and power losses and hence reduction in power quality. Current and voltage Harmonics have negative effect on protective devices e.g. tripping of relays and melting of fuses. Current harmonics especially of third order have very much negative impact of on transformer and neutral conductor. Third order current harmonic have interference effect on telecommunication signal. So as a protective step neutral conductor with larger cross sectional area is used in commercial places [8]. The DC component of current in transformer can cause disturbance in flux, resulting in excursion of flux which results in saturation of magnetic core of transformer. Also the return path for the dc current through earth sometime introduces corrosion to the metallic structure buried in earth [9]. Power quality also has impact on economic losses on both utilities and customer's side. Power quality impact on utility side is that it results in mal-operation of protective devices, metering devices and overheating of transmission cables. The assessed power losses in Pakistan are $30 \%$ of the total production [10].

\section{CUSTOM DEVICES FOR MITGATION OF POWER QUALITY PROBLEMS}

N.G. Hingorani in 1995 introduced custom power (CP) in [4]. Custom power device is a combination of different power electronic elements or a tool box that can be connected with transmission network to help in improving power quality of distribution system. The entities of $\mathrm{CP}$ are gate turn off Thyristors and insulated gate bipolar transistors (IGBTs) combined with microprocessor and different circuit elements.

Voltage sag is because of short circuiting. Excessiveness in voltage sag can be determined by fault time and magnitude of supplied current. Fault clearing time can be reduced consuming CLF (current limiting fuses) [5] and solid state circuit breaker [6]. A current limiting fuse has to be replaced after melting. CLF can remove the flaw in $1 / 2$ cycle, where is solid state circuit breaker remove the flaw in one and $1 / 2$ cycle but is a multipurpose device.

Quality of power is judged by the difference between the qualities of power supplied to the quality of power required for the safe operation of electrical load. So keeping this point in mind power quality problems can be resolved into main three ways

- Power supply disturbances should be reduced 
- The immunity to disturbances at the load equipment should be reduced

- For sensitive load there must be some control unit to mitigate power quality problems between load side and source.

Considering different cases any suitable option can be selected. This proposed work focus on the third option.

The immunity to disturbances in load side can be mitigated using proper control and correcting devices, so that the load does not extract excessive current and excessive apparent power out of the supply. This is applicable to new devices, for old devices we cannot use the new control system [11]. Power quality problems are not new to this system but are existed from the time when voltages were transferred through feeders for the first time for long distances. Control system at that time were passive circuits at that power electronic were not invented [12]. They were named as conventional facilitation technique. The passive circuits were designed using inductors and capacitors. These passive circuits are currently utilized in transmission and distribution circuits for harmonics, reactive power, and voltage compensation, but special care should be taken while selecting these tuned circuits as they may add additional problems to the system. Passive circuits at high power level make a system bulky and prone to many problems.

For correction of power factor synchronous condensers, Capacitors bank, and SVCs are applied to distribution network [13]. Response of synchronous condenser and capacitor banks are slow. SVCs may add additional harmonics which need filtration. The advances in power electronics like digital signal processing (DSP) make this possible to achieve fast correcting response. These advance power electronic devices make this possible to achieve maximum improvement in quality of power and reducing the essential problems. These advance electronic power devices were named as custom power devices (CPD) [3].

CPDs can be categorized into two main groups, namely compensating devices and network-reconfiguring devices. The network-reconfiguring type has (SSCL) Solid State Current Limiter, (SSB) Solid State Breaker, (SSTS) Solid State Transfer Switch. Compensating type has (DSTATCOM) Distribution Static Compensator, (DVR) Dynamic Voltage Restorer, and (UPQC) Unified Power Quality Conditioner.

The compensating type controllers are used for compensation of reactive control, currents harmonics, voltage problems, power factor correction and THD. DSTATCOM can be utilized for the adjustment of Reactive control and current harmonic [14]. Voltage related problems can be compensated using Dynamic Voltage Restorer. UPQC is used for the compensation for both current and voltage. The proposed work relies on UPQC; this device is composed of both shunt and series power filtering. The reasons behind harmonic distortion describe in this paper are: extension in the network of power system, commonly used electrical devices made of advance power electronic and excessive use of nonlinear loads. This paper also significantly improves the decrease in harmonics by employing D-STATCOM and DG.
The measurements for total harmonic distortions are determined and their result for all buses is then presented. The result presented by author verify that DG and D-STATCOM optimal for decrease in harmonics. The efficiency in the voltage shape of a network, reduction in the system losses, and reduction in the disturbances of total harmonics are the results obtained by the use of D-STATCOM and DG. So THD is reduced to $6 \%$ [15]. In this paper author uses FACT device for mitigation of single line harmonics and three phase harmonics. The device used is static synchronous series compensator (SSSC). It also helps in mitigating noise from system voltages and currents. By the use of SSSC the THD has reduced to $6 \%$ from $16.6 \%$ [16].

For enhancing the decontrolled complex system is examined using genetic algorithm. For the assessment purposes two kinds of FACTS procedures are implemented, first TCSC (Thyristors-Controlled-Series-Capacitor) and second SVC (Static-VAR-Compensator), for the consistency of voltage, decrease in the line losses and minimization of congestion. The develop control algorithm is analyzed and applied to IEEE-30 bus transmission system. The study of transaction for bilateral and multilateral systems and issues like line outage and loading of uniform line has also been done. In this paper enhanced power system consistency and loss of power mitigation by introducing TCPS (ThyristorsControlled Phase Shifter) is examined. The phase shifter distribution factor is the source of control of losses of energy [17]. In this paper clarified optimization technique by placing different Flexible alternating transmission system device on bus system of IEEE-57 is used as a base for propose technique. The propose system is tested on two conditions (1) normal condition and (2) line contingency condition in which FACTS devices were used. In this paper a Hybrid Fish method was used to manage complexity of the system that is called Bee Swarm Optimization technique. There are two basic methods of this technique: (1) Fish School Search (FSS) technique and (2) Artificial Bee Colony (ABC) technique. IEEE-30 bus transmission method was used to check the proposed technique, the result proved to be effective for the reduction of complexity [18].

To analyze bilateral and multilateral agreement there are two types of market models. For the management of congestion, researcher utilizes the association of the FACTS devices with transmission lines. There are two variable Reactance's that were modeled using FACT devices, TCSC and SVC. TCSC has the explanation of two situations or case. The settlement of TCSC for the congested line in the inductive mode is in the first case and settlement for slightly loaded buses in capacitive mode is the second case. By using the trial and error process normal settlement of TCSCs are applied. In this paper the researcher give detailed study of Genetic Algorithm based technique for the reduction of congestion by using specific settlement of FACTS device with transmission line [19]. In this paper author practically use a technique to mitigate the congestion. The technique used is called TCSC in series that is associated with transmission line for attaining the level of congestion called is Line Utilization Factor (LUF). 
For controlling the active power flow and management for congestion an uncertain logic controller is utilized. Modified bus system of IEEE-14 is considered for analysis of suggested method. After that, comparison is done between the results of both uncertain logic and sensitivity process. So, the concluding studies showed that for the management of congestion process the most applicable method is uncertain method [20].

In this paper the author suggested a method for the mitigation of transmission line congestion that is called Particle Swarm Optimization (PSO). The settlement of proposed method of Unified Power Flow Controller (UPFC) is normally designed for specific size. For the special requirement of transmission line UPFC is personalized solutions. A test system of 5-bus is considered to be examined using UPFC method. Results obtained shows that the congestion problem has solved [29]. In this paper author analyzed the proper settlements for the FACTS devices to overcome the congestions in power supply lines. To determine the effectiveness the analysis of TCSC (Thyristors-ControlSeries-Capacitor) and Statics-Synchronous-SeriesCompensators devices has applied to modified bus test system of IEEE-14. Reduction in transmission line problems a comparison process has been used in this paper [21]. In this paper author uses an appropriate FACT devices for the settlement of reactive power. FACTS devices are used in appropriate location with specific index order to decrease maximum Reactive Power losses [31]. Author in this paper proposed a multi objective management method that is based on congestion management in power system. The functionality define by this method has three goals (1) operating cost, (2) voltage, and (3) transient stability margin, which is improved as proposed by author. The effective settlement and size of FACTS devices are managed by the suggested method based on congestion transmission line and by significance citation using LMP (Locational Marginal Prices) [22].

In this paper "current limiting fuses" is designed for fault clearing time and reduction in magnitude of fault current. The design helps in reduction of fault clearing time, and sag problem in voltage is limited to only half cycle. The disadvantage of this system is that after melting of fuse human intervention is necessary for the replacement of the fuse. In this paper solid state circuit breaker is proposed for fault clearing. It is a combination of Gate Turn off (GTO) and Thyristors switches. The design helps in clearing fault within half cycle. Solid state circuit breaker is a multifunction device and has an advantage over current limiting fuse of auto reclosing after fault clearance. This paper proposed solidstate-fault-current-limiter. This device is based on gate turn off circuitry which adds an inductor in series when fault is detected in power system. After clearing the faults the inductor is remove [23].

\section{CONFLICT OF INTEREST}

The author has no conflict of interest.

\section{CONCUSLION}

Quality of Power plays in important role in power system. Low power quality effect consumer in many ways, it causes distortion, electrical interruption in power appliances, decaying life of industrial equipment's, and more seriously it can be detrimental to life of human being. Considering different cases any suitable option can be selected for power quality improvement.

\section{REFERENCES}

[1] Sankaran, C., Power quality. 2001: CRC press.

[2] Bollen, M.H., Understanding power quality problems, in Voltage sags and Interruptions. 2000, IEEE press.

[3] Ghosh, A. and G. Ledwich, Power quality enhancement using custom power devices. 2012: Springer Science \& Business Media.

[4] Zhang, S., et al., Control Strategy for Dynamic Voltage Restorer Under Distorted and Unbalanced Voltage Conditions. IEEE International Conference On Industrial Technology (ICIT), 2019: p. 411-416.

[5] Akagi, H., New trends in active filters for power conditioning. Industry Applications, 1996. 32(6): p. 1312-1322.

[6] Alferov, Z.I., The history and future of semiconductor heterostructures. Semiconductors, 1998. 32(1): p. 1-14.

[7] García, O., et al., Single phase power factor correction: A survey. IEEE Transactions on Power Electronics, 2003. 18(3): p. 749-755.

[8] Grady, W.M. and S. Santoso, Understanding power system harmonics. IEEE Power Engineering Review, 2001. 21(11): p. 8-11.

[9] Marketos, P., A.J. Moses, and J.P. Hall, Effect of DC voltage on AC magnetisation of transformer core steel. J. Elect. Eng, 2010. 61: p. 123125.B

[10] Hussain, Z., et al., Technical Losses Ratio: Analysis of Electric Power Transmission and Distribution Network. INTERNATIONAL JOURNAL OF COMPUTER SCIENCE AND NETWORK SECURITY, 2018. 18(9): p. 131-136.

[11] Dugan, R.C., et al., Electric power systems quality. 2004, McGraw-hill.

[12] Myneni, H., G.S. Kumar, and D. Sreenivasarao, Dynamic dc voltage regulation of split-capacitor DSTATCOM for power quality improvement. IET Generation, Transmission \& Distribution, 2017. 11(17): p. 4373-4383.

[13] Ramachandaramurthy, V.K., et al., Supervisory control of dynamic voltage restorers. IEE Proceedings-Generation, Transmission and Distribution, 2004. 151(4): p. 509-516.

[14] Gupta, A.R. Effect of optimal allocation of multiple DG and DSTATCOM in radial distribution system for minimizing losses and THD. in 2017 7th International Symposium on Embedded Computing and System Design (ISED). 2017. IEEE.

[15] Kullarkar, V.T. and V.K. Chandrakar. Power quality improvement in power system by using static synchronous series compensator. in 2017 2nd International Conference for Convergence in Technology (I2CT). 2017. IEEE.

[16] Esmaili, M., H.A. Shayanfar, and R. Moslemi, Locating series FACTS devices for multi-objective congestion management improving voltage and transient stability. European journal of operational research, 2014. 236(2): p. 763-773.

[17] Kai, X. and G. Kusic, Application of thyristor-controlled phase shifters to minimize real power losses and augment stability of power systems. IEEE Transactions on Energy Conversion, 1988. 3(4): p. 792-798.

[18] Rahimzadeh, S. and M.T. Bina, Looking for optimal number and placement of FACTS devices to manage the transmission congestion. Energy conversion and management, 2011. 52(1): p. 437-446.

[19] Thangalakshmi, S. and P. Valsalal, CONGESTION MANAGEMENT USING HYBRID FISH BEE OPTIMIZATION. Journal of Theoretical \& Applied Information Technology, 2013. 58(2).

[20] Kulkarni, P.P. and N. Ghawghawe. Optimal placement and parameter setting of TCSC in power transmission system to increase the power 
transfer capability. in 2015 International Conference on Energy Systems and Applications. 2015. IEEE.

[21] Dhansekar, P. and K. Elango, Congestion management in power system by optimal location and sizing of UPFC. IOSR Journal of Electrical and Electronics Engineering, 2013. 6(1): p. 49-53.

[22] Kojovic, L. and S. Hassler, Application of current limiting fuses in distribution systems for improved power quality and protection. IEEE Transactions on Power Delivery, 1997. 12(2): p. 791-800.

[23] Smith, R., et al., Solid-state distribution current limiter and circuit breaker: application requirements and control strategies. IEEE Transactions on Power Delivery, 1993. 8(3): p. 1155-1164. 